\title{
Estación Plaza Matadero: Habi(li)tar el vacío
}

\author{
Felipe Corvalán T. / Profesor Guía: Pablo Gil D.
}

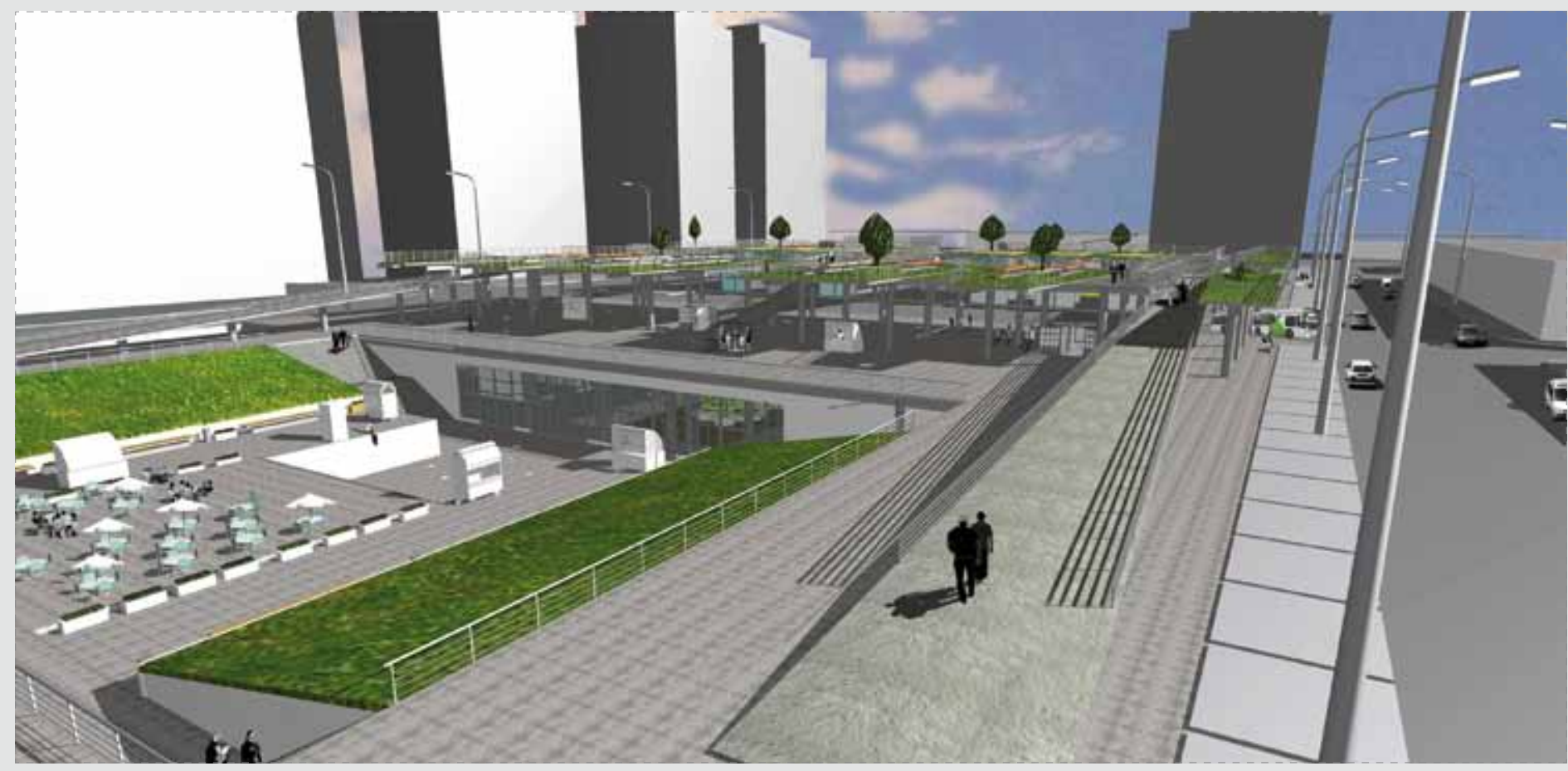

Las expresiones arquitectónicas asumen el rol de evidencia sintomática del habitar de una cultura, marcadas por el tiempo en que se desplazan y convertidas en la interfase entre el hombre y el territorio que habita.

El predominio de la virtualidad supone la metáfora de un mundo que se desprende de su cuerpo, ausente de «evidencias» y de aquel pulso que construye el tiempo en función de la relación de los cuerpos en el espacio.

Si bien la arquitectura nunca termina de cerrar la experiencia en el espacio, ni a través de su estructura formal, ni de su conformación programática, se propone la recuperación de la arquitectura como dispositivo, membrana que propicia eventos operativos de usotransformación del espacio por parte de los individuos que lo habitan. La recuperación de la ciudad como territorio de «deseo».

El barrio Franklin es sinónimo de un programa arquitectónico consolidado como dispositivo de acción, definido a partir de la relación entre las acciones de uso y los atributos físicos-espaciales del lugar. La mantención del barrio como centro de intercambio comercial y social, requiere su incorporación al mapa metropolitano, síntoma de su vigencia como subcentralidad alternativa. Una arquitectura fundada en la incertidumbre del encuentro, necesita un diálogo permanente entre la ciudad y aquellas áreas características que la definen, evitando que la movilidad y los desplazamientos sean sinónimos de fragmentos anónimos y desterritorializados.
En tal contexto, surge la Estación Plaza Matadero, medio de reconocimiento, y constitución fronteriza. Estación/plaza, habilitar/habitar, dispositivo/fricción. Si el espacio colectivo desaparece como lo solíamos conocer, debemos imaginarlo a partir de los modos y maneras que la sociedad contemporánea usa para relacionarse.

Aventura de rehacer y reorganizar espacios colectivos invadidos por estructuras de desplazamiento. Reconstitución que asegura la continuidad. Continuidad que requiere la reconstitución. Reconocimiento de formas de uso ya insaturadas como características esenciales del barrio. Dispositivo y fricción, membrana y relato, espacio y tiempo, medio vinculante y significativo. 


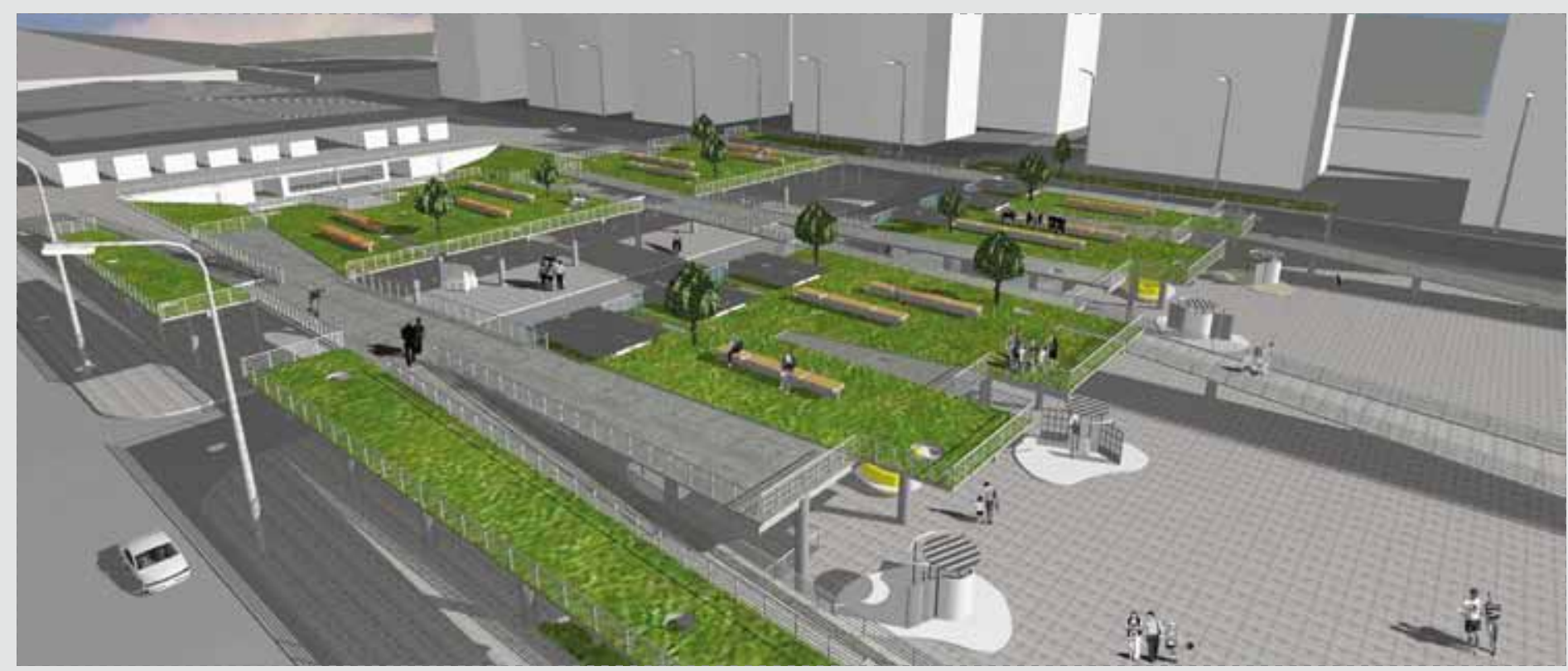

0000000000000000000000000

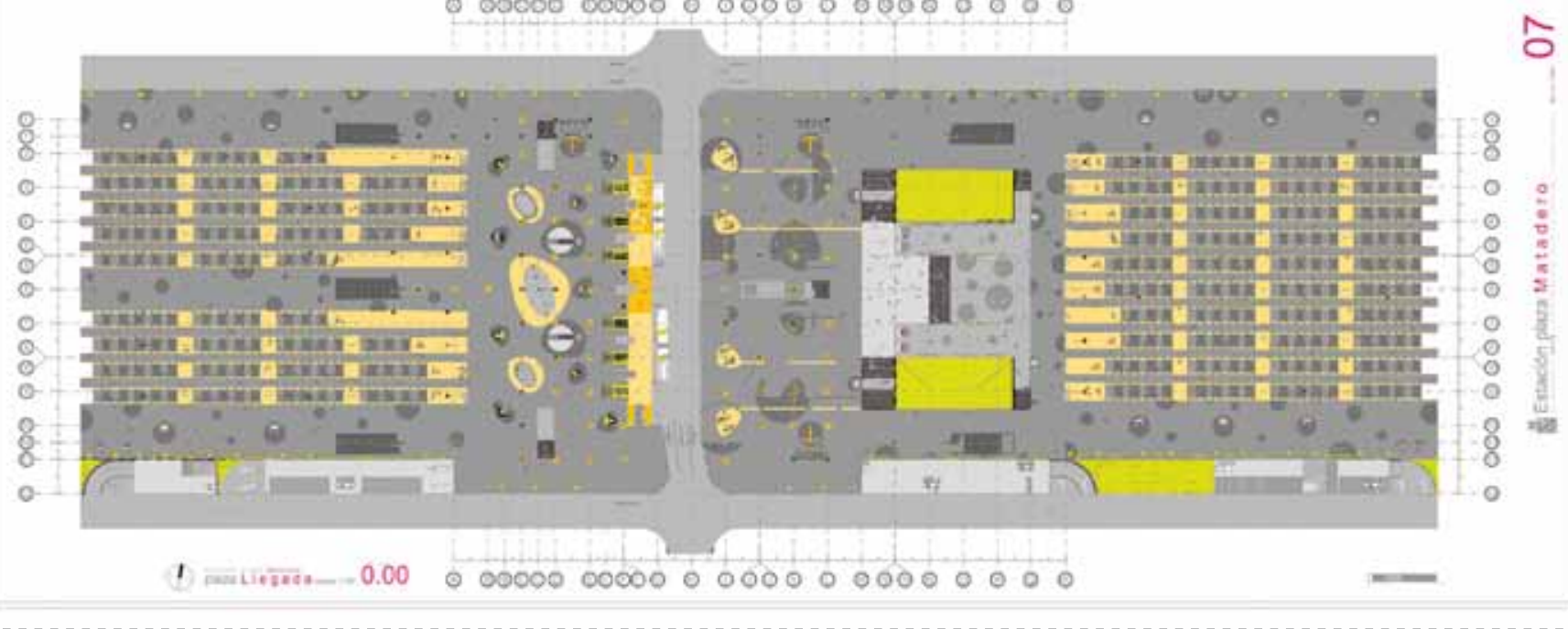

- 000000000000000000000

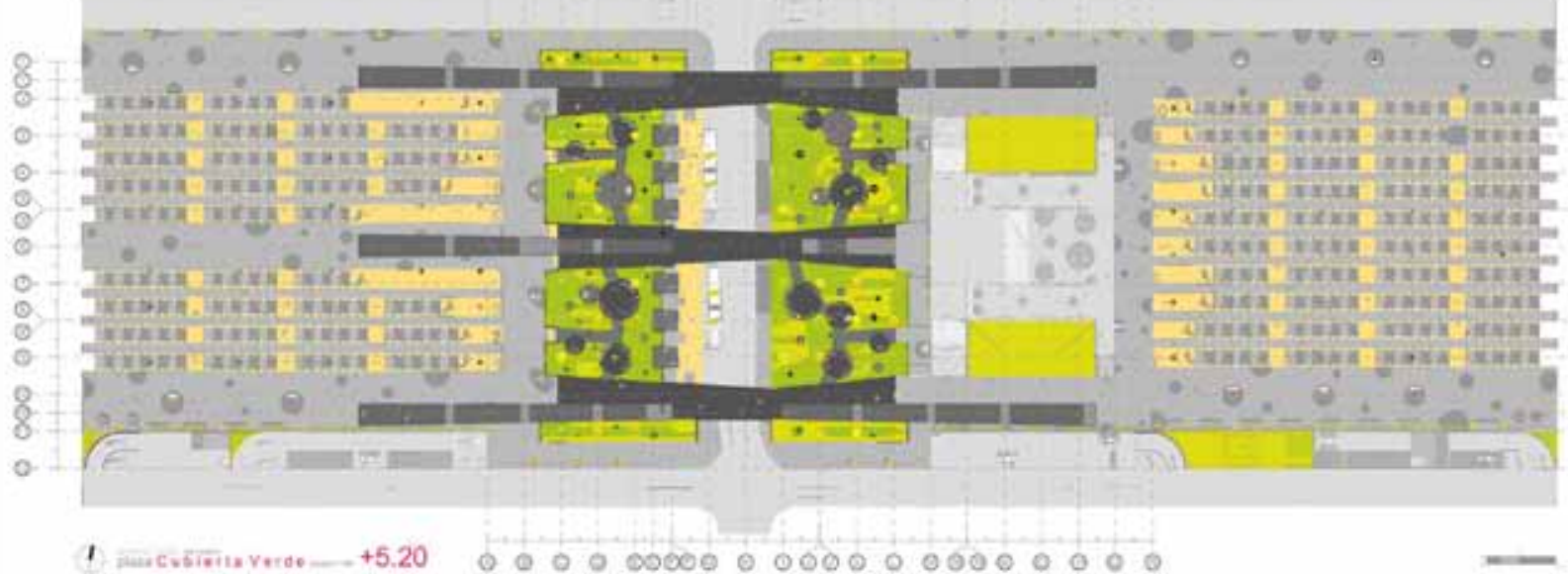

